\title{
ALEXANDER DE LAVAUX EN ZIJNE GENERALE KAART VAN SURINAME 1737 DOOR
}

MR. R. BIJLSMA.

In het jaar 1731 kwamen Directeuren der Societeit van Suriname tot de ervaring, dat de bestaande kaarten hunner kolonie niet toereikend waren, om een juist overzicht te geven van den staat van het grondbezit en de ligging der plantages langs de groote rivieren. Bovendien leverde het bezwaren op, dat de kaarten onvoldoende waren tot het nauwkeurig volgen der destijds uit Suriname ontvangen brieven, waarin Gouverneur Carel Aemilius Henry de Cheusses rapporteerde over tochten, ondernomen tegen de weggeloopen slaven, die zich ophielden bij de Saramaccarivier. Bij schrijven van 30 Maart 1731 droegen Directeuren der Societeit den Gouverneur op, vooreerst om steeds de grondbrieven of warrands der nieuw uitgegeven gronden ter goedkeuring aan hen over te zenden, en vervolgens om er zorg voor te dragen, dat de kaart der kolonie door de landmeters daar te lande werd geperfectioneerd en de namen van de eigenaren der plantages er op werden aangebracht. In zijn antwoord deelde de Gouverneur mede, de orders betreffende de grondbrieven en de kaart der kolonie te zullen uitvoeren.

Over de voorbereidende werkzaamheden tot het karteeren vernamen Directeuren der Societeit een en ander door de gouverneursmissive van 18 Mei 1732. Wat de Generale kaart van de rivieren in deze kolonie betreft - zoo meldt De Cheusses - heb ik ter bevordering daarvan aan de landmeters gelast, om op 
de secretarie na te zien de aanwezige grondbrieven en geapprobeerde kaarten. De grondbezitters, wier warrands en kaarten ontbraken, zouden order moeten krijgen, hunne gronden opnieuw te laten uitmeten; zij konden dan later hun goedgekeurde kaarten en behoorlijke warrands ter secretarie der Kolonie doen registreeren. Met behulp van deze stukken zou de Generale kaart van de rivieren in Suriname gemakkelijk zijn op te maken. De maatregel leverde bovendien het voordeel op, dat hier en daar plantages zouden worden gevonden van grooter uitgestrektheid dan deze toekwam, doordat vroeger niet nauwkeurig gelet was op het stellen van de limietpalen en het openkappen van de scheidlinies; de vrijkomende kleine stukken land waren dienstig tot het aanleggen van koffieplantages, waarvoor niet zooveel terrein noodig was als voor een suikerplantage.

Voordat nog de gouverneursmissive in Amsterdam was gearriveerd, hadden Directeuren reeds zorg gedragen voor de indienstneming van een nieuwen landmeter, Ulrich Abels van Elselo, die in Franeker had gestudeerd en hun zeer was aanbevolen. Zij meldden dit aan den Gouverneur, er bij voegend, dat zij eene accurate kaart van de Kolonie verlangden, en in het bijzonder van de plantages in het stroomgebied der Suriname-rivier van af Paramaribo tot den Parnassusberg; landmeter Van Elselo zou hiertoe werkzaam kunnen zijn.

Gouverneur Carel Aemilius Henry de Cheusses beantwoordde in September 1732 dit schrijven met eene verwijzing naar zijne missive van $18 \mathrm{Mei}$; volgens het daarbij voorgestelde plan, zouden de planters de onkosten der uitmeting dragen en zou het mogelijk zijn binnen korten tijd een correcte kaart te vervaardigen, niet alleen van de Suriname-rivier, maar ook van de Commewijne, Cottica en Perica alsmede van al de bewoonde kreeken.

De gouverneursmissive van Mei 1732 was na ontvangst in handen gesteld eener commissie, die daarover rapport uitbracht in de vergadering van Directeuren 
der Societeit van 4 Februari 1733, in welke bijeenkomst tevens de missive van September 1732 werd behandeld. Directeuren hechtten hun goedkeuring aan het plan van Gouverneur de Cheusses en droegen hem op, een placaat in dien zin uit te vaardigen. Uit de op deze wijze verkregen kaarten der gronden zouden dan de landmeters in Suriname een Generale kaart der Kolonie kunnen samenstellen.

Onder dagteekening van 13 Mei 1733 werd het placaat uitgevaardigd, waarbij de Gouverneur aan de grondbezitters gelastte hunne geapprobeerde kaarten en warrands ter secretarie te doen registreeren; grondbezitters zonder geapprobeerde kaarten zouden gehouden wezen hunne gronden op nieuw te doen uitmeten, en wel die aan Suriname-rivier met Paulus- en Surinokreek vóór ultimo November 1733, en die aan de rivieren Commewijne, Cottica en Perica met onderhoorige kreeken en spruiten vóór ultimo Mei 1734.

Het is niet aannemelijk, dat dit placaat veel zal hebben uitgewerkt. Ook had men een slechte keus gedaan met den landmeter Ulrich Abels van Elselo, die naar het oordeel van den Gouverneur onbekwaam bleek in zijn vak. En toen Gouverneur Carel Aemilius Henry de Cheusses in Januari 1734 kwam te overlijden, moest het wel schijnen, alsof het plan eener kaart voorloopig onuitgevoerd zou blijven.

Toch was zulks niet het geval. In Mei 1734 werden Directeuren der Societeit verrast door een brief uit Suriname, geschreven door Alexander de Lavaux, vaandrig in dienst der Societeit en gezworen landmeter der provincie Suriname, waarin deze te kennen gaf, dat hij ruim twee jaren bezig was geweest met een Generale kaart van Suriname en hiermede bijna was gereed gekomen; met consent van Directeuren wilde hij de kaart doen drukken en verzocht daartoe verlof, om in 1735 naar het moederland over te komen. De beschikking van Directeuren viel in den meest gunstigen zin uit: zij verklaarden aan De Lavaux, dat zijn bericht betreffende de kaart hun zeer aangenaam was, stonden 
hem vrije overtocht en terugtocht toe, bevorderden hem tot luitenant en stelden bij finale uitvoering van het plan nieuwe bewijzen hunner goede gezindheid in het vooruitzicht.

Alexander de Lavaux was in 1729 op 25-jarigen leeftijd in dienst der Societeit getreden; hij was geboortig van Berlijn en had naar zijne opgave in Pruisischen dienst den rang van luitenant en ingenieur gehad. Met een benoeming tot landmeter en gereformeerd officier was De Lavaux naar Suriname vertrokken, waar hij bij de militie den rang van vaandrig gekregen had. Van De Lavaux's werkzaamheid als landmeter zijn tal van bewijzen tot ons gekomen in den vorm van kaarten van Surinaamsche gronden, die hij in de jaren 1731-1733 voornamelijk in Commewijne en Cottica en in 1735 aan de Suriname-rivier kreeg op te meten. Als vaandrig verwierf hij bekendheid met de onbekende streek tusschen den bovenloop der Suriname en de Saramacca, waarheen hij in het jaar 1731 een tweetal tochten tegen de weggeloopen slaven medemaakte. De eerste tocht van dit jaar tegen de wegloopers bij de Saramacca stond onder bevel van den vaandrig De Boisguignon; De Lavaux maakte zich bij deze onderneming aan insubordinatie schuldig, werd daarom na afloop in arrest gesteld, doch verkreeg op advies van den krijgsraad gratie, op voorwaarde dat hij een nieuwe expeditie moest medemaken om zijn gedrag te verbeteren. Van zijn betere gezindheid deed De Lavaux al dadelijk blijken op de onderneming, in de maand September 1731 aangevangen onder leiding van kapitein Bley; hij maakte van de gelegenheid gebruik om een fraaie kaart te vervaardigen van den loop der Surinamerivier boven de bij den Parnassusberg gelegen plantage Berg-en-Dael. Gouverneur De Cheusses zond deze kaart, voorzien met een opdracht van De Lavaux aan Directeuren der Societeit, naar Amsterdam over, tegelijk met een kaart van de Saramacca-rivier, vervaardigd door den landmeter Jacob Hengeveld, die de expeditie tegen de wegloopers als luitenant van de burgerwacht had medegemaakt. 


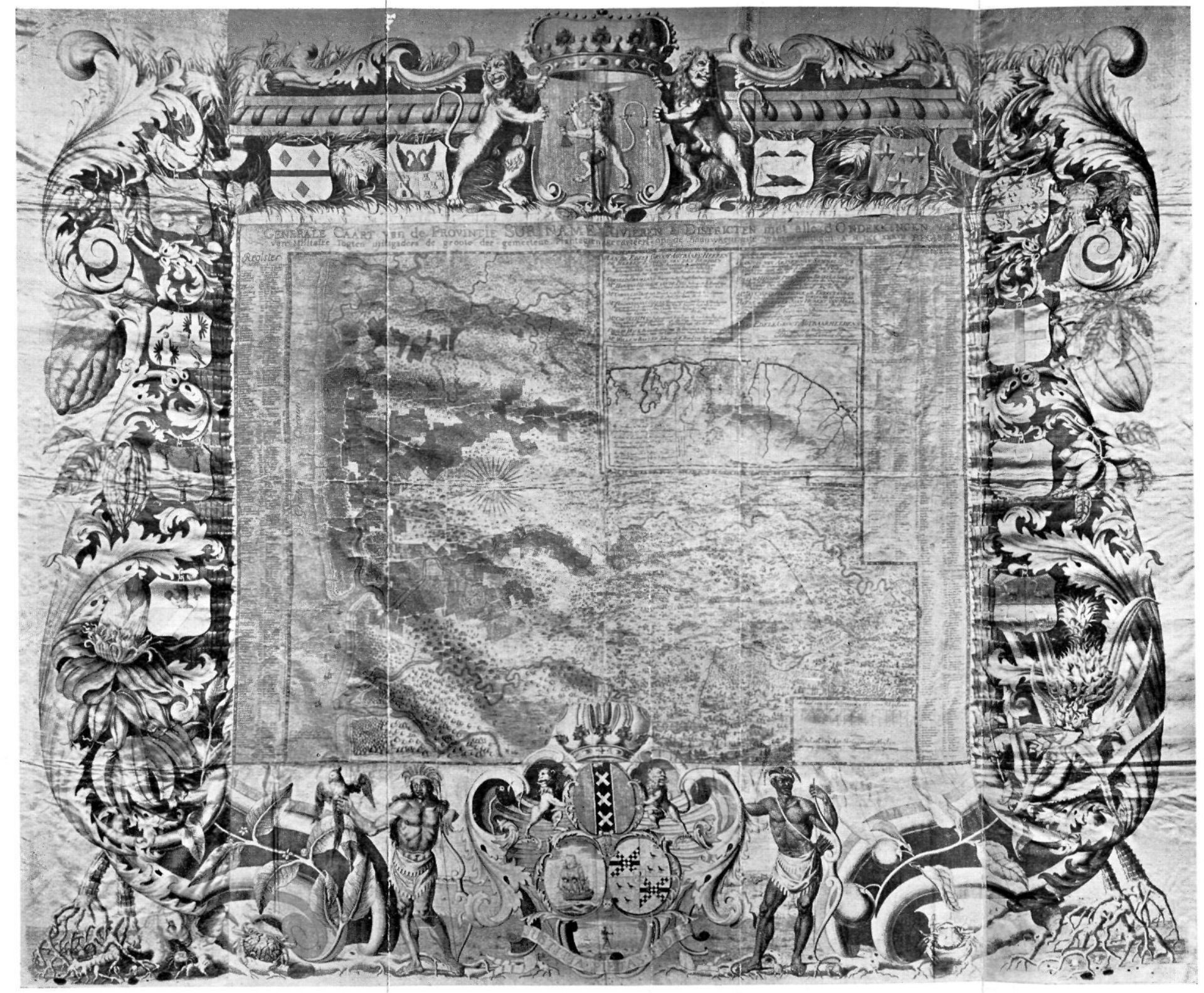

REPRODUCTIE NAAR EEN OP WITTE ZIJDE GEDRUKT EXEMPLAAR IN DE COLLECTIE VAN JHR. J.W. SIX VAN VROMADE 


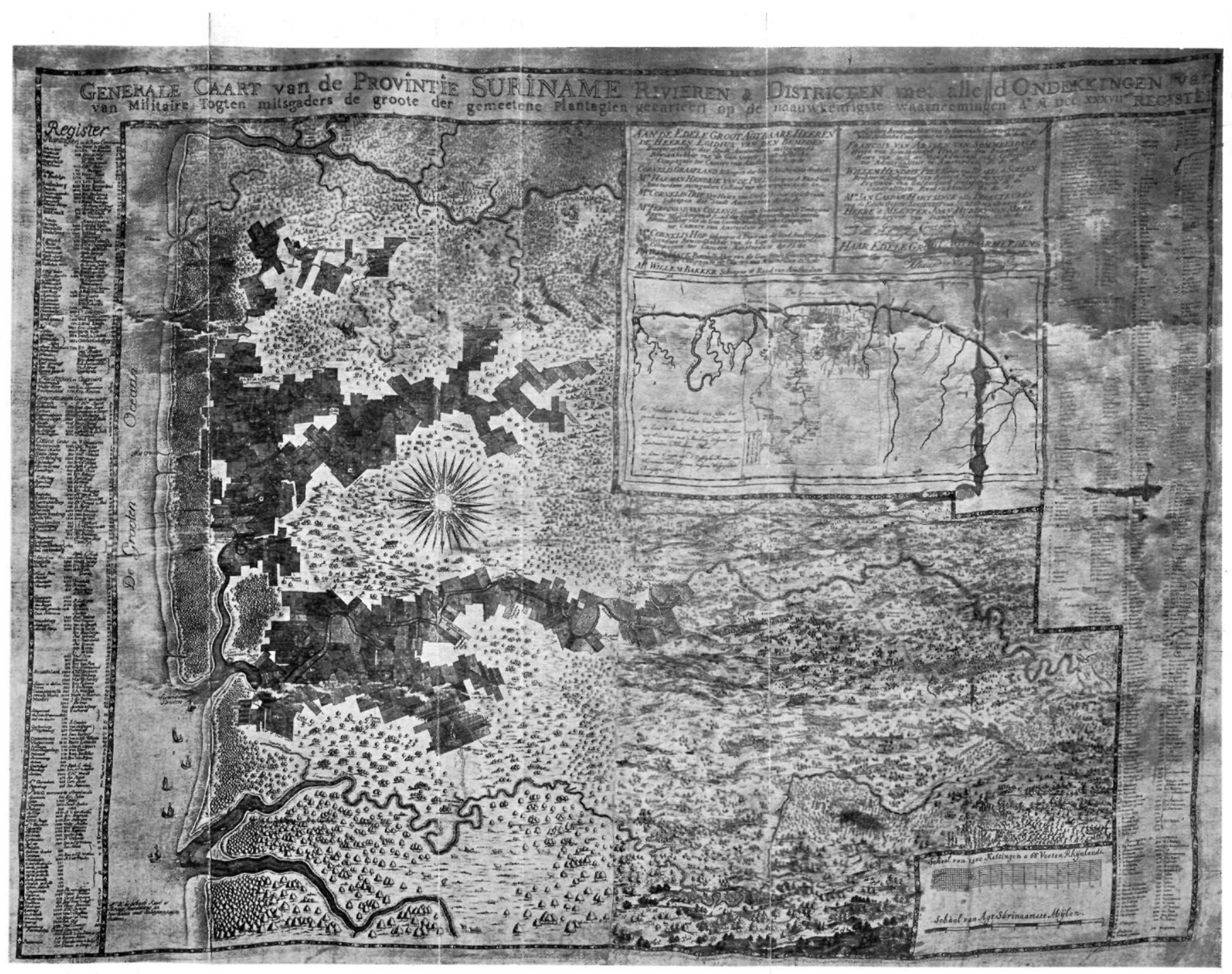

RE:PRODUCTIE NAAR EEN EXEMPLAAR ZONDER DEN RAND IN DE COLLECTIE VAN JHR. J.W. SIX VAN VROMADE. 
Voor zijn arbeid aan de Generale kaart van Suriname kon De Lavaux tegen het einde van het jaar 1734 op den steun rekenen van den nieuw opgetreden Gouverneur Jacob Alexander Henry de Cheusses, die daartoe in zijn instructie speciale orders van Directeuren der Societeit had ontvangen. In zijn missive van 14 Januari 1735 deelde de Gouverneur mede, hoe De Lavaux zich bij hem beklaagd had, dat vele eigenaren en directeuren van plantages weigerden de kaarten en warrands van hunne gronden te vertoonen, uit vrees, dat daaruit zoude blijken, dat gronden, welke zij nu in naam bezaten doch niet in cultuur hadden gebracht, als niet tijdig bebouwde gronden aan de Societeit moesten vervallen. Zonder deze gegevens zou het niet mogelijk zijn de Generale kaart in korten tijd te voltooien; de Gouverneur was echter voornemens, ten einde dit fraaie en nuttige werk zoo spoedig mogelijk tot perfectie te doen brengen, de grondbezitters te gelasten hunne bewijsstukken over te leggen. Nog voor de maand Januari ten einde was zou evenwel Gouverneur Jacob Alexander Henry de Cheusses reeds zijn overleden.

In Juli 1735 scheepte luitenant De Lavaux zich in voor de reis naar het moederland, waartoe hem door Directeuren der Societeit vergunning was gegeven. De reis verliep weinig voorspoedig, daar het schip niet zeewaardig bleek; op het eiland Martinique ging de reiziger op een franschen bodem over, die hem naar Havre-de-Grace bracht. Nog trof hem het ongeluk, dat op zijn overtocht de meeste papieren van het water leden. Toen De Lavaux dan ook in Januari 1736 ter vergadering van Directeuren der Societeit te Amsterdam compareerde, moest hij mededeelen, dat hij met den meesten spoed met behulp zijner aanteekeningen de kaart zoude herstellen en perfectioneeren.

$\mathrm{Na}$ enkele maanden kon een aanvang worden gemaakt met het op koper brengen van de kaart. Voor het einde van het jaar werd de eerste maal loon aan een plaatsnijder uitbetaald; de onkosten van het snijden kwamen tegen het einde van 1737 ongeveer 1250 gulden 
te beloopen. Hoezeer Directeuren met de voltooiing van het werk waren ingenomen, blijkt uit hunne resolutie van 3 Januari 1738. Alexander de Lavaux werd bevorderd tot kapitein bij de militie in Suriname en tevens verkreeg hij eene aanstelling als ingenieur. Het was de bedoeling van Directeuren, dat hij in deze laatste qualiteit als deskundige in vestingbouw, na de oplevering van het groote fort, dat destijds in de kolonie gebouwd werd, de inspectie zou hebben van de fortificatiewerken aldaar. Bovendien besloten Directeuren een aanschrijving te richten tot het Hof van Politie in Suriname, om bij uitsluiting aan De Lavaux op te dragen, het uitmeten van nieuw uit te geven gronden, ten einde te beter de Generale kaart te kunnen vergrooten.

Voor de moeite, aan het karteeren en doen drukken besteed, en voor de opdracht der kaart aan Directeuren, lieten deze aan den vervaardiger de keuze tusschen de beschikking over de koperen platen of een belooning van 1000 gulden; De Lavaux prefereerde het geld. In Augustus 1738 verscheen hij voor de laatste maal in de vergadering van Directeuren, om zijn eed als kapitein af te leggen en kennis te geven van zijn aanstaand vertrek naar Suriname.

Het opschrift van De Lavaux's kaart luidt:

Generale Caart van de Provintie Suriname, rivieren en districten met alle d'ondeckingen van militaire togten mitsgaders de groote der gemeetene plantagien, gecarteert op de naauwkeurigste waarneemingen. Anno MCDDXXXVII.

Op de kaart is bijgevoegd een lijst bevattend de namen der ongeveer 400 plantages, gelegen in het stroomgebied van Suriname, Commewijne, Cottica en Perica, de namen der eigenaren en de grootte der landen. Ook verzuimde De Lavaux niet, er op aan te brengen het traject van de beide door hem in 1731 medegemaakte tochten tegen de wegloopers bij. de Saramacca. De kaart wordt omsloten door een breede randversiering, bestaande uit de wapens van de Staten-Generaal, van de Societeit van Suriname, en van de Directeuren der Societeit, en uit vruchten en andere voortbrengselen der Kolonie. 
Een 50-tal exemplaren der kaart werd naar Suriname gezonden, ten geschenke voor de Raden en andere gequalificeerde en gedistingeerde personen aldaar.

De verdere carrière in Suriname van den kapitein en ingenieur Alexander de Lavaux zou geheel anders uitvallen, dan te verwachten viel. Hij maakte de reis over Nieuw-Engeland en arriveerde eerst in 1740 in de Kolonie Suriname. Eenigen tijd na zijn aankomst richtte hij tot het Hof van Politie het verzoek, hem zijn achterstallige gage als landmeter uit te betalen; het Hof willigde dit verzoek in, behalve voor den termijn zijner reis via Nieuw-Engeland, waaraan hij een jaar besteed had.

Bij Gouverneur Van de Schepper blijkt De Lavaux niet voldoende erkenning zijner verdiensten te hebben gevonden: de commissie van ingenieur werd hem althans niet uitgereikt. Over deze en andere zaken gebelgd, vatte De Lavaux het plan op de Kolonie te verlaten, volgens zijn zeggen om in Holland recht te zoeken. Zonder waarschuwing scheepte hij zich einde Januari 1741 in op een Engelsch schip naar Sint-Eustatius, vanwaar hij vervolgens naar de Engelsche kolonie Sint-Christophe vertrok. Hierdoor maakte De Lavaux zich aan desertie schuldig. Het Surinaamsche gouvernement verwittigde onmiddellijk Directeuren der Societeit en deze vroegen door bemiddeling van de gezanten der Republiek te Londen en Parijs de gevangenneming en uitlevering aan de Engelsche en Fransche regeering aan, voor het geval De Lavaux op een der West-Indische eilanden werd aangehouden. Het signalement teekent hem als: redelijk kloek van persoon, doch schraal en mager; bruin van tronie; zwaar van baard, trekkend naar het blauwe; de oogen uit het hoofd puilend; gewoonlijk een zwarte pruik dragend. Inmiddels werd de deserteur bij verstekvonnis van den krijgsraad in Suriname van zijn militairen rang vervallen verklaard. Tot de aanhouding op Sint-Christophe en de uitlevering verleende het 
Engelsche gouvernement der West-Indische eilanden zijn medewerking en in November 1741 werd De Lavaux in Suriname aangebracht, waar hij op het Fort Zeelandia gevangen werd gezet. In plaats van het verstekvonnis zou de krijgsraad thans een nieuwe uitspraak moeten geven. Over de aanhouding van De Lavaux werd echter van Engelsche, hem bevriende zijde uit West-Indië een bericht naar Londen gezonden, waardoor de Engelsche regeering van inzicht veranderde en aan haar gezant te 's-Gravenhage opdroeg, ten behoeve van den gevangene te intervenieeren. Naar aanleiding dezer interventie schreven Directeuren der Societeit den Gouverneur van Suriname aan, de procedure niet te verhaasten en acht te slaan op de tusschenkomst van den koning van Groot-Brittagne. Aan den Engelschen gezant echter gaven Directeuren te kennen, dat het gerecht zijn loop moest hebben.

De Raad-Fiscaal in Suriname, Mr. Jacob van Halewijn van Werve, zat, zwaarwichtig als hij was, niet weinig met de zaak verlegen. Bij het verhoor van den gevangene, dat in Juni 1742 een aanvang nam, betrof de ondervraging vooral de verstandhouding tusschen De Lavaux en den Engelschen gouverneur van SintChristophe, aan wien hij een kaart van Suriname en een door hem uitgewerkt plan van Sint-Eustatius had geschonken. Het duurde tot Juni van het volgend jaar 1743 voor de krijgsraad uitspraak deed; of liever het kwam niet tot een uitspraak, aangezien 5 leden eene veroordeeling wilden tot ontzetting uit den militairen dienst en verwijdering uit de Kolonie, terwijl 4 leden, onder wie de Commandeur, die beweerde een dubbele stem te hebben, zich voor de doodstraf uitspraken. De beslissing was dus onzeker en Gouverneur Mauricius wendde zich, ten einde raad, tot Directeuren der Societeit om hun meening over het vonnis te vernemen; deze echter antwoordden, dat zij zich van alle inmenging in de rechtspraak wenschten te onthouden. Gelukkig voor den deserteur was Gouverneur Mauricius hem welgezind. Waarschijnlijk heeft De Lavaux de lange 
en harde voorgevangenis op den duur niet kunnen verdragen en is hij daardoor aan hallucinaties en zinsverbijstering gaan lijden. Hierop althans wijzen de lange memories die hij van tijd tot tijd aan den Gouverneur richtte ${ }^{1}$ ). In deze stukken, van 20 tot 30 bladzijden groot, beklaagt hij zich over een complot der artilleristen op het fort Zeelandia, die zich aan allerlei godslastering, duivelbezwering en anderen hocuspocus schuldig maken. $\mathrm{Zij}$ bezorgden den ingenieurlandmeter slapelooze nachten, doordat zij met behulp van flesschen, waterpas geplaatst boven bakken met water, en door lampen hem 's nachts in zijn cel alles deden vernemen, wat op hun afschuwelijke bijeenkomsten gezegd en gedaan werd. De brieven, met vaste hand grootendeels in vlotte fransche zinnen geschreven, getuigen allerminst van hersenverzwakking. De gevangene trachtte zich trouwens den tijd te korten door goede lectuur; tegenover den franschen predikant Audra sprak hij zijn voorkeur uit voor leerzame boeken zonder verzinsels, zede-beschrijvingen, historie, gedenkschriften, biografieën van bekende mannen, reisverhalen enz., lectuur dus, die voor een positief verstand paste.

Gouverneur Mauricius uitte in zijn missiven aan Directeuren der Societeit twijfel, of De Lavaux geheel bij zinnen was; en ook oordeelde hij, dat diens desertie meer aan étourderie dan aan kwaadaardigheid was te wijten. Aan een doodvonnis schijnt de Gouverneur later al niet meer gedacht te hebben; hij vroeg zich zelfs af, of het wel doelmatig was een bekwaam man als De Lavaux, die alle fort en faible van de kolonie kende, te laten vertrekken en hem zoodoende te dwingen zich in vreemden dienst te begeven.

Het vonnis, door den krijgsraad in Juni 1743 geveld, werd geredigeerd als eene veroordeeling tot ontzetting uit den militairen dienst en verwijdering uit de kolo-

1) Deze stukken zijn in origineel of afschrift bewaard gebleven in de serie Brieven en Papieren uit Suriname aan Directeuren der Societeit. Jaargang 1743 II folio 428 en $890 ; 1744$ I folio 408. 
406 ALEX. DE LAVAUX EN ZIJNE KAART V. SURIN. 1737.

nie. Deze beslissing werd in Februari 1744 aan den gedetineerde bekend gemaakt. Enkele weken later scheepte Alexander de Lavaux zich in, om Suriname te verlaten, het land, waarmede hij zoo goed vertrouwd was, en dat hij in zijn betere jaren met kunde en ambitie had gediend. 